\title{
Pedagogia, educação especial e educação inclusiva na UNESP: história e trajetória*
}

\author{
CRISTIANE REGINA XAVIER \\ FONSECA-JANES \\ Universidade Estadual Paulista, Marília, SP, Brasil \\ CELESTINO ALVES DA SILVA JÚNIOR \\ Universidade Estadual Paulista, Marília, SP, Brasil \\ ANNA AUGUSTA SAMPAIO DE \\ OLIVEIRA \\ Universidade Estadual Paulista, Marília, SP, Brasil
}

\section{INTRODUÇÃO}

O curso de Pedagogia constituiu-se ao longo da história da educação para hoje ser considerado o locus de formação dos profissionais que pretendem atuar na docência da educação infantil, nas séries iniciais do ensino fundamental e no o ensino médio, bem como na gestão de sistemas educacionais. Entretanto, essa definição de atuação dos pedagogos não se constituiu de maneira harmoniosa.

* Este texto é resultado dos estudos desenvolvidos na tese de doutorado intitulada "A formação dos estudantes de pedagogia para a educação inclusiva: estudo das atitudes sociais e do currículo", desenvolvida por Cristiane Regina Xavier Fonseca-Janes no Programa de Pós-Graduação em Educação na área de Concentração em Ensino na Educação Brasileira, na linha de pesquisa Educação Especial no Brasil, sob a orientação do professor doutor Sadao Omote. O projeto de pesquisa contou com o financiamento da Fundação de Amparo à Pesquisa do Estado de São Paulo (FAPESP) (Processo n. 07/53237-1). 
Embates políticos e epistemológicos ocorreram para que chegássemos a essa quase consensual definição do seu campo de atuação.

A literatura consultada sobre o processo de formação dos cursos de Pedagogia no Brasil indica que eles passaram por várias crises de identidade: a do campo de atuação dos profissionais que neles eram formados, a da delimitação de seu objeto de estudo, a de seu reconhecimento perante os outros cursos de licenciatura e, por fim, uma que se estende por anos, que é a questão da nova estrutura curricular após as Diretrizes Curriculares Nacionais (DCNs) para os cursos de Pedagogia. Essa questão pode ocorrer por meio de exaustivos debates sobre um possível caráter minimalista, por alguns teóricos, ou seu caráter generalista, por outros, incindindo na formação do pedagogo.

É nesse panorama conflituoso que iremos observar a constituição dos cursos de Pedagogia no interior paulista, uma vez que a sua criação na Universidade Estadual Paulista (UNESP) surge atrelada aos institutos isolados, o que irá gerar muitas transformações internas, tanto no remanejamento de docentes quanto na extinção de alguns cursos.

O entendimento de seu processo de constituição, tanto do curso de Pedagogia quanto o da criação dos cursos de Pedagogia da UNESP, torna-se possível ao compreendermos a dinâmica que se estabeleceu no interior de cada um deles. Assim, organizamos este artigo em dois tópicos. No primeiro, discutimos a busca do curso de Pedagogia por uma identidade e a questão da extinção das habilitações e suas implicações na formação do pedagogo e também o impacto na formação por uma perspectiva inclusiva. E no segundo sugerimos ser a heterogeneidade um dos fatores constitutivos e enriquecedores das três formas de organização dos cursos de Pedagogia da UNESP.

\section{HISTÓRICO DO CURSO DE PEDAGOGIA: A BUSCA E O POSSÍVEL (DES)ENCONTRO DE UMA IDENTIDADE}

A Pedagogia é descrita por Saviani (2008, p.xii) como um campo epistemológico bem definido e entendida "como teoria e prática da educação" que ao longo da história da civilização ocidental foi se firmando como "correlato da educação" (Saviani, 2007, p. 1), ou seja, ao pensarmos no termo pedagogia, esse está fortemente associado à noção de educação.

A Pedagogia, ao desenvolver-se dentro da prática educativa, tornou-se "a teoria ou a ciência dessa prática sendo, em determinados contextos, identificada com o próprio modo intencional de realizar a educação" (Saviani, 2008, p. 1).

Esse autor evidencia, por meio de algumas correntes filosóficas, que nem todos os estudiosos da área têm um consenso sobre a autonomia científica da Pedagogia. Na perspectiva do idealismo, a Pedagogia se dissolveu na filosofia e passou a ser considerada "filosofia aplicada" (idem, p. 2). Já na perspectiva do positivismo, a Pedagogia foi associada à prática educativa pela busca de sua cientificidade. Para Saviani, a busca pela cientificidade da Pedagogia apenas transferiu a sua submissão à filosofia para as ciências empíricas. 
Embora o termo Pedagogia não estivesse grafado literalmente em documentos ou em grandes tratados filosóficos, a sua essência sempre esteve presente na história da Antiguidade, da época medieval e no início da época moderna, conforme é possível verificar em Aranha (2000), Cambi (1999), Jaeger (19--), Luzuriaga (1955), Marrou (1966). Para Saviani, é a partir do século XIX que a utilização do termo Pedagogia passa de fato a ser generalizada com o sentido de "conexão entre a elaboração consciente da ideia da educação e o fazer consciente do processo educativo" (Saviani, 2008, p. 6).

O referido autor aponta que é no século XX, no final dos anos de 1970, que a Pedagogia se voltou para a busca de sua autonomia científica. Na leitura de Saviani (2007), autores como Schimied-Kowarzik, Fraboni e Genovesi foram de extrema relevância para essa discussão. Esses autores argumentam que a Pedagogia é uma ciência autônoma, com campo teórico e métodos próprios, cujos resultados geram conhecimentos, experimentações e técnicas no campo educacional. Entretanto, ainda não é consensual na área da educação o entendimento da Pedagogia como uma ciência. Saviani alerta os estudiosos da área que, se a Pedagogia for uma teoria da educação, ela deve ser entendida como teoria da prática educativa. Assim "o conceito de pedagogia se reporta a uma teoria que se estrutura a partir e em uma função da prática educativa" (idem, p. 2). Seu objeto de estudo é então equacionar os problemas pertinentes à relação educador-educando, professor-aluno, por meio de orientações sobre o processo de ensino e de aprendizagem. ${ }^{1}$

Para Libâneo (2010), a Pedagogia é "uma das ciências da educação - mas a pedagogia organiza, sintetiza as contribuições de outras ciências aplicadas à educação". Essas outras ciências seriam a Antropologia, a Sociologia, a Psicologia, a Filosofia etc., ${ }^{2}$ quando por meio de seus objetos específicos de estudo procuram compreender as diferentes dimensões que constituem a prática pedagógica: o contexto social, a concepção de homem e sociedade, as interações sociais e os fundamentos epistemológicos que sustentam a ideia de educação.

Para Saviani, arraigado ao termo Pedagogia sempre esteve presente o problema da formação de professores. A necessidade de se formar docentes para o exercício do magistério foi discutida por Comenius, ${ }^{3}$ mas é somente após a Revolução Francesa, com o surgimento dos problemas da instrução popular, que

1 Salientamos que são de nosso conhecimento as discussões acerca da dicotomia entre teoria e prática no campo educacional que adveio desse conceito de pedagogia. Optamos por não entrar nessa temática por ela não fazer parte, no momento, de nossos objetivos de estudo.

2 Anotações realizadas pelo próprio autor nos rascunhos da pesquisadora Cristiane Regina Xavier Fonseca-Janes, no dia 23 de abril de 2010, durante o XV Encontro Nacional de Didática e Prática de Ensino (ENDIPE), cujo título foi "Convergências e tensões no campo da formação e do trabalho docente: políticas e práticas educacionais”.

3 A saber, o primeiro estabelecimento para formação de professores foi o Seminário dos Mestres, no ano de 1684, em Reims, França, por São João Batista de La Salle (Saviani, 2008, p. 2). 
essa questão assume a exigência de um posicionamento institucional. ${ }^{4}$ Saviani lembra que a formação de professores foi necessária desde a Antiguidade, mas nos períodos anteriores ao século XIX o que prevalecia no processo de formação era "o princípio do 'aprender fazendo"' (Saviani, 2008, p. 7).

Com a necessidade de se universalizar a instrução elementar no século XIX, surgem as organizações de sistemas nacionais de ensino (Aranha, 2000; Cambi 1999) e com eles aparecem os problemas de formação de professores em larga escala. Para minimizar esses problemas, de acordo com Saviani, foram criadas as escolas normais de nível médio e de nível superior. A primeira formava os profissionais para atuarem como professores no nível primário e a segunda para a atuação no nível secundário.

Ainda para Saviani (2008), esse sistema originou dois modelos de formação: (1) o modelo dos conteúdos cultural-cognitivos e (2) o modelo pedagógico-didático.

No primeiro modelo, a ênfase na formação é dada "na cultura geral e no domínio específico dos conteúdos da área do conhecimento correspondente à disciplina que o professor irá lecionar" (idem, p. 8). No segundo modelo, a formação dos professores está associada à efetivação do "preparo pedagógico-didático" (idem, ibidem).

Na perspectiva de Saviani, a questão da formação de professores não esteve associada ao modelo de formação dos "conteúdos cultural-cognitivos" que estava diretamente vinculado às universidades.

O modelo adotado pelas universidades desde sua origem pautou-se na ideia de que a "formação pedagógico-didática" seria o resultado do "domínio dos conteúdos do conhecimento logicamente organizado" (idem, p. 9) e sua efetivação viria com a própria prática docente ou mesmo por meio do "treinamento em serviço".

O curso de Pedagogia no Brasil foi criado por meio do decreto n. 1.190/1939, ${ }^{5}$ dentro da organização da Faculdade Nacional de Filosofia. Silva (2009) e Gatti

4 Processo que culmina com a criação das escolas normais, sendo a primeira estabelecida em 1795, em Paris. Depois foram também criadas na Itália, Alemanha, Inglaterra e Estados Unidos.

5 Mesmo que a criação do curso de Pedagogia seja datada desse período, salientamos que a lei n. 10, de 1835, determina a criação da primeira escola normal no Brasil, na província do Rio de Janeiro. Segundo Tanuri (2000), essa escola foi suprimida em 1949. Em 1859, com a lei n. 1.127, de 4 de fevereiro, determinou-se a criação de outra escola normal na província do Rio de Janeiro. Para Tanuri (2000, p. 64), "em todas as províncias as escolas normais tiveram uma trajetória incerta e atribulada, submetidas a um processo contínuo de criação e extinção, para só lograrem êxito a partir de 1870". De acordo com Saviani (2008), com a lei n. 88, de 8 de dezembro de 1892, se estabelece a criação do Curso Superior da Escola Normal para a formação dos professores secundários, mas este não fora de fato implantado. Também convém lembrar que a Universidade de São Paulo (USP), por meio da Faculdade de Filosofia, Ciências e Letras, desde 1934 já colaborava com a formação de professores tanto das escolas secundárias quanto das instituições de ensino superior. Entretanto, essa formação era desvinculada da atividade prática, era mais voltada à investigação científica e ao domínio dos conteúdos. A formação propriamente dita de professores acontecia no Instituto de Educação. Esse instituto foi criado pelo 
(2010) argumentam que o início do curso surge da necessidade de se formar docentes para aturarem na escola secundária.

Ele se estruturou originalmente como um curso de bacharelado com duração de três anos e a licenciatura com mais um ano, por meio do curso de didática - o famoso esquema " $3+1$ " que compõe a maioria dos cursos de bacharelado e licenciatura.

Para Saviani (2007, 2008), esse modelo de curso de Pedagogia não vinculou os processos de investigação acerca dos temas e problemas educacionais como era feito nas áreas de filosofia, ciências e letras.

Com a aprovação da lei n. 4.024, de dezembro de $1961,{ }^{6}$ a primeira Lei de Diretrizes e Bases da Educação Nacional (LDB), houve uma reestruturação curricular no curso de Pedagogia: passaria de três para quatro anos e os egressos seriam titulados com o bacharelado e a licenciatura.

No curso de Pedagogia, o egresso do bacharelado exercia o cargo de técnico em educação e o da licenciatura atuava principalmente na docência do curso normal; este último não era exclusividade do pedagogo, uma vez que quem tivesse uma titulação em ensino superior também poderia atuar nessa função (Silva, 2009; Scheibe; Aguiar, 1999).

Na opinião de Saviani (2007), a nova reestruturação curricular do curso manteve seu caráter generalista, não inserindo ainda as habilitações. A novidade foi a abertura para que as instituições distribuíssem as disciplinas ao longo de quatro anos.

Embora o esquema " $3+1$ " tenha sido revogado, na prática as disciplinas de Psicologia da Educação, Elementos de Administração Escolar e Didática eram cursadas no segundo e terceiro anos do curso de Pedagogia; já a disciplina de Prática de Ensino era cursada no quarto ano. Para Silva (2009), esse modelo dicotômico perdurou mesmo com as mudanças na legislação educacional.

Convém salientar que as críticas quanto à indefinição do curso e a controvérsia sobre sua manutenção ou extinção não são recentes, pois o conselheiro Valnir Chagas, no parecer n. 251, aprovado pelo Conselho Federal de Educação (CFE) em 1962, escreveu um texto no qual criticava os problemas do curso de Pedagogia.

decreto n. 5.884, de 21 de abril de 1933, na gestão de Fernando Azevedo no cargo de diretor do Departamento de Educação do Estado de São Paulo. O Instituto de Educação tinha em sua estrutura o Jardim de Infância, Escola Primária, Escola Secundária, Escola de Professores, Centro de Psicologia aplicada à Educação e Centro de Puericultura. A Escola de Professores oferecia a formação de professores primários, formação pedagógica aos professores secundários e especialização para a formação de diretores e gestores. $\mathrm{O}$ instituto foi extinto pelo decreto estadual n. 9.269, de 25 de junho de 1938, e absorvido pela Faculdade de Filosofia, Ciências e Letras da USP, especificamente na seção de educação.

6 Saviani argumenta que nesse ínterim houve a criação de vários órgãos que influenciaram o campo educacional, a saber: Instituto Nacional de Estudos Pedagógico (INEP) (1938), a Coordenação de Aperfeiçoamento de Pessoal de Nível Superior (CAPES) (1951), o Centro Brasileiro de Pesquisas Educacionais (CBPE) (1955) e os Centros Regionais de Pesquisas Educacionais (CRPEs) (1995). 
Nesse texto, segundo Saviani (2007), o conselheiro já vislumbrava a tendência de se formar os professores do primeiro ciclo do ensino fundamental em nível superior e os especialistas em educação em nível de pós-graduação. Essa também parece ser a essência das DCNs de 15 de maio de 2006. Ainda, para Saviani, o parecer do conselheiro Valnir Chagas levaria com essa organização curricular, em longo prazo, à extinção do curso de Pedagogia.

Como vivemos em uma sociedade dinâmica, cujas transformações são constantes na história das mentalidades, com o curso de Pedagogia não poderia ser diferente e, como tal, sua matriz curricular passou por mais uma transformação com a vigência da lei n. 5.540, de 28 de novembro de 1968, a qual previa a reforma universitária. Nessa reforma deliberou-se que seria facultativo ao curso de Pedagogia o oferecimento das habilitações em Supervisão, Administração e Inspeção Educacional, bem como em outras especialidades.

O curso de Pedagogia, como consequência da Reforma Universitária, em 1969 passou por nova regulamentação com o parecer n. 252/1969 do CFE, de autoria do relator Valnir Chagas, que resultou na resolução n. 2/1969.

A sugestão do relator foi no intuito de que o curso de Pedagogia se estruturasse de tal forma que propiciasse subsídios para a formação do generalista e do especialista. O esquema “ $3+1$ ” retorna, mas com outra característica: a formação do generalista nos três primeiros anos e do especialista no último ano.

A matriz curricular do curso de Pedagogia, a partir da resolução n. 2/1969, estruturou-se com dois eixos de formação: o primeiro composto de uma base comum e o outro eixo com as disciplinas para as habilitações específicas. O eixo da base comum era composto de disciplinas, tais como: Sociologia Geral, Sociologia da Educação, Psicologia da Educação, História da Educação, Filosofia da Educação e Didática. O segundo eixo contemplava as seguintes habilitações: Orientação Educacional, Administração Escolar, Supervisão Escolar, Inspeção Escolar e Ensino das Disciplinas e Atividades Práticas dos cursos normais. Essa estruturação da matriz curricular permaneceu em vigor até a aprovação da LDB n. 9.394, de 20 de dezembro de 1996, mesmo com as inúmeras tentativas de mudança pelos movimentos organizados dos educadores e de iniciativas do próprio CFE.

Saviani (2007) alerta para a essência das reestruturações curriculares. Na sua visão, a estruturação curricular pautada na formação do especialista era permeada pela lógica do mercado, que necessitava do técnico. Esse autor ainda alerta que Valnir Chagas integrou - como relator e mentor principal - o grupo de trabalho (GT) responsável pela lei n. 5.692, de 11 de agosto de 1971, que regula o sistema de ensino de acordo com a nova legislação. Ele também evidencia que, durante o período de 1973 a 1975, Chagas escreveu um livro com um conjunto de argumentos para que o curso de Pedagogia fosse substituído pelos "estudos superiores de educação", argumentando ser o curso de Pedagogia restrito e o segundo mais amplo e completo para a formação dos profissionais que atuariam no sistema educacional.

Para Silva (2006, p. xix), a questão que se colocou com as indicações do relator Valnir Chagas, em 1973, ao propor a "desestruturação do curso de Pedagogia", 
não foi apenas a de extinção do curso, mas sim a identidade do próprio curso. As indagações começaram a surgir uma após a outra, como numa sequência de pedras de dominó em queda, pois, ao se questionar a manutenção ou não do curso de Pedagogia, colocava-se em xeque não só o problema de sua identidade, mas também se o curso possuía conteúdo próprio e campo de conhecimento específico. $\mathrm{Na}$ opinião de Silva (2006, p xxi), o que se questionava na época não era o campo teórico do curso de Pedagogia, mas sim "a maneira de alocar os estudos referentes a ele na estrutura geral dos cursos superiores de educação".

Silva (2006, p. xxvi) argumenta que, ainda que houvesse essas discussões advindas dos questionamentos sobre a identidade do curso de Pedagogia, "na prática a estrutura do curso era mantida nos termos configurados a partir de 1969".

Para Brzezinski (2002), as medidas adotadas pelo relator com seus indicativos sobre o curso de Pedagogia aprovados pelo CFE desencadearam uma movimentação dos educadores a favor do curso. Para a autora (2002, p. 22), esse movimento era contrário às "possíveis mudanças que, em sua essência, propugnavam a extinção do Curso de Pedagogia e descaracterizavam ainda mais a profissão de pedagogo, que paulatinamente seria extinta".

Para Saviani (2007), um dos fatores que contribuíram para o enfraquecimento do curso de Pedagogia ocorreu na década de 1960, com a instalação dos programas de pós-graduação em educação. Por um lado, houve a aproximação das áreas afins das ciências humanas e a criação do "espaço acadêmico da educação", com os programas mostrando a sua pujança; por outro lado, o curso de Pedagogia "definhava e se debatia em uma crise de tal profundidade que projeta a impressão de que jamais conseguirá dela sair" (idem, p. 11). Essa crise é intensificada com a introdução na LDB da constituição dos Institutos Superiores de Educação e das Escolas Normais Superiores.

A partir da década de 1980, por influência de pesquisas educacionais e reivindicações do movimento de educadores e de movimentos populares, algumas faculdades de educação "suspenderam ou suprimiram as habilitações convencionais [...], para investir num currículo centrado na formação de professores para as séries iniciais do ensino fundamental e curso de magistério" (Libâneo, 1998, p. 38). Assim, o curso de Pedagogia começou a ganhar a especificidade de formação de profissionais para docência. Quanto à educação infantil como finalidade educativa, ela só emerge na LDB n. 9.394/1996.

Saviani $(2008,2007)$ e Libâneo (1998) declaram que esse movimento de educadores em defesa do curso de Pedagogia se configurou no comitê Pró-Participação na Reformulação dos Cursos de Pedagogia e Licenciatura, em 1980, ${ }^{7}$ na Primeira

7 Embora Saviani (2008) e Libâneo (1998) apontem que o movimento dos educadores em defesa do curso de pedagogia tenha se configurado no comitê em 1980, Silva Júnior (2010) relata que ela já ocorrera anteriormente, em 1978, na Universidade Estadual de Campinas (UNICAMP). Pagotto (1995, p. 47) e Aguiar et al. (2006) confirmam as datas de Saviani (2008) e Libâneo (1998) quanto à Primeira Conferência Brasileira 
Conferência Brasileira de Educação. Em 1983, esse comitê se transformou na Comissão Nacional de Reformulação dos Cursos de Formação do Educador (CONARCFE), constituindo-se em 1990 na Associação Nacional pela Formação dos Profissionais da Educação (ANFOPE), que continua até o momento.

O movimento dos educadores foi de grande relevância para a busca da identidade do curso de Pedagogia, emergindo nos debates internos duas "ideias-forças" (Saviani, 2007, p. 10) em torno de sua formação, a saber: (a) o eixo centrado na docência e (b) o eixo centrado na "base comum nacional". Assim, houve uma forte tendência de as instituições estruturarem o curso de Pedagogia pela perspectiva da formação de professores para habilitação no magistério para atuação no ensino fundamental, mas evitando o segundo eixo, pois ele "não coincide com a parte comum do currículo nem com a ideia de currículo mínimo"(idem, p. 11). Entretanto, essa ideia foi incorporada ao texto da LDB.

Gatti (2010) afirma que com a publicação da LDB houve propostas de alterações para as instituições que formavam professores, mas é apenas em 2002 que efetivamente foram promulgadas as DCNs para a formação desses profissionais e, nos anos posteriores, consequentemente, começam a ser aprovadas as diretrizes para os cursos de licenciaturas. Decorrente desse momento histórico, foram aprovadas em 2006 as DCNs para o curso de Pedagogia.

Scheibe (2010) argumenta que as diretrizes para o curso de Pedagogia originaram do movimento de educadores e de grande parte das instituições universitárias em resistência à baixa qualificação dos egressos do curso. A proposta das diretrizes foi a primeira ação concreta do movimento, "estabelecendo para o curso de Pedagogia um currículo de formação do pedagogo, bacharel e ao mesmo tempo licenciado para a docência da educação infantil e os anos iniciais do ensino fundamental" (idem, p. 553).

Podemos pensar então que no cerne desse debate estava a questão da busca de uma identidade pelo curso de Pedagogia. No Brasil, essa questão da identidade dos profissionais do curso de Pedagogia sempre esteve presente desde seu início, em 1939. Silva (2006) mostra quatro períodos em que essa questão se desenvolveu:

1) Período das regulamentações: identidade questionada, de 1939 a 1972; instituiu a organização do curso de Pedagogia sob o crivo da legislação;

2) Período das indicações: identidade projetada, entre 1973 e 1978; caracterizou-se pelos encaminhamentos das indicações do conselheiro Valnir Chagas sobre o curso de Pedagogia ao CFE;

3) Período das propostas: identidade em discussão, de 1979 até 1998; inúmeros encaminhamentos de propostas sobre a formação do educador foram

de Educação realizada em São Paulo no mês de abril de 1980. De acordo com Pagotto (1995, p. 46) e com Aguiar et al. (2006, p. 823), no ano de 1978, em Campinas, ocorreu o I Seminário de Educação Brasileira, cuja temática era a preocupação com a reformulação dos cursos de pedagogia. 
direcionados aos órgãos governamentais por professores e estudantes universitários;

4) Período dos decretos: identidade outorgada, de 1999 em diante; caracterizado pelo momento histórico que conteve "documentos de caráter impositivo firmados no âmbito da Presidência da República com a função, ainda que indireta, de estabelecer limites às funções do curso de Pedagogia" (Silva, 2006, p. 6).

Parece que Silva (2006) concorda com a afirmação de que realmente a tão procurada identidade do curso de Pedagogia, desde 1939, hoje foi encontrada. Entretanto, ela não foi cedida, mas conquistada - talvez não a conquista que todos os pedagogos, assim como Silva e nós, gostariam que fosse, a identidade sonhada e discutida no interior das lutas dos movimentos dos educadores, mas já foi um pequeno progresso. Não é a identidade apontada por Libâneo (1998, p. 51-52) em seus estudos sobre a amplitude que as discussões sobre a área de atuação do pedagogo estavam denotando, que extrapolavam a esfera escolar; de modo contrário, essa conquista definiu o papel do pedagogo apenas no sistema escolar.

Talvez, uma das saídas para extrapolarmos os muros da escola seja a possibilidade de ampliar as discussões sobre a gestão de sistemas educacionais, uma vez que gerir sistemas sobre a questão da educação é algo que pode ser realizado em diversificados espaços, escolares ou extraescolares. Enxergamos as implicações dessa singela conquista, principalmente por sabermos que outras batalhas se travaram para ampliar a identidade conquistada e construída por meio de muita luta.

A legitimidade da identidade do pedagogo para a docência na educação infantil, nos cinco primeiros anos do ensino fundamental e para o ensino médio na modalidade normal, bem como para atuar na gestão escolar, foi instituída para o curso de Pedagogia pelas DCNs (Brasil, 2006). Contudo, não temos dúvidas de que o debate sobre a identidade do pedagogo não está encerrado, pois, além das questões já levantadas, as diretrizes introduzem um alinhamento conceitual entre ser professor e ser pedagogo. Estaria o pedagogo restrito apenas à docência? Ao se manter o eixo centrado na docência, não se restringiu o campo de atuação científica do pedagogo? Gostaríamos de insistir que o pedagogo é aquele que tem domínio sobre os processos educativos e pode exercê-lo em sistemas escolares ou não escolares; além disso, é preciso preservar o seu campo de atuação científica.

Scheibe (2010), pautada nos estudos de Saviani (2007), assinala que as diretrizes são restritas e ao mesmo tempo extensivas:

Restritas, [...] no essencial, naquilo que se refere ao que configura a pedagogia como um campo de conhecimentos e experiências; e excessivas no acessório, ao incorporar a linguagem atualmente em evidência, de expressões tais como: "conhecimento ambiental ecológico"; "pluralidade de visões de mundo"; "interdisciplinaridade, contextualização, democratização"; "ética e sensibilidade afetiva e a estética"; "exclusões sociais, étnico-raciais, econômicas, culturais, religio- 
sas, políticas"; "diversidade; diferenças; gêneros; faixas geracionais"; "escolhas sexuais", entre outras. (Scheibe, 2010, p. 558)

Na opinião de Scheibe (2010), as diretrizes permitem que cada curso tenha uma significativa autonomia e flexibilização em seus componentes curriculares por meio do Projeto Político Pedagógico (PPP) e de suas matrizes curriculares, que permitem opções diferenciadas em sua constituição formativa. Gatti (2010, p. 487), ao analisar as diretrizes, anota que o curso de Pedagogia "passa a ter amplas atribuições, embora tenha como eixo a formação de docentes para os anos iniciais da escolarização".

Também há outro ponto para ser assinalado. A extinção das habilitações, embora afinada com as proposições das entidades representativas da Pedagogia, traz implicações para a formação em áreas importantes do conhecimento pedagógico, como a Administração Escolar e a Educação Especial. Aqui destacaremos a questão da Educação Especial, visto que as diretrizes nacionais "simplificam a ideia de uma Educação Inclusiva e esvaziam o papel da Educação Especial no processo de constituição de ambientes adequados para a aprendizagem com êxito de alunos com deficiência" (Oliveira,2009, p. 261), além de destituirem do pedagogo a atuação na área da Educação Especial, uma vez que essa formação não acontecerá mais nos cursos de Pedagogia.

Apesar de as diretrizes apontarem a diversidade e as necessidades educacionais especiais como eixos importantes de formação, faz-se necessário destacar que não se deve confundir a formação na perspectiva da Educação Inclusiva com a Educação Especial, pois são domínios de conhecimentos e de atuação que se diferenciam na prática educacional.

Bueno (1999,p. 14) já mostrava a necessidade de se pensar tanto em uma quanto em outra formação, ou seja, "dois tipos de formação profissional: dos professores do ensino regular [...] e dos professores especializados", assinalando que a perspectiva inclusiva não extingue a formação/atuação em Educação Especial. Vários autores (Giroto; Castro, 2011; Glat; Pletsch, 2010; Mendes, 2009; Michels, 2011; Naujorks; Real; Mohr, 2011; Piccolo, 2009; entre outros) enfatizam a importância da formação na perspectiva inclusiva, mas não deixam de mencionar a necessidade de se pensar na Educação Especial e no trabalho em cooperação entre as áreas, para que realmente se possa atender adequadamente àqueles com necessidades educacionais especiais.

No artigo $5^{\circ}$ das DCNs são delineados dezesseis itens com o perfil dos egressos do curso de Pedagogia, sendo que seis deles tratam especificamente da Educação Inclusiva. Quanto à inclusão dos alunos com deficiências, foi possível perceber apenas dois itens - os incisos $\mathrm{V}$ e X. O inciso $\mathrm{V}$ afirma que o pedagogo deve "reconhecer e respeitar as manifestações físicas, cognitivas, emocionais, objetivas dos educandos nas suas relações individuais e coletivas" (Brasil, 2006, p. 11). Mas como proceder para efetivar o processo de ensino e aprendizagem? Alunos com deficiências muitas vezes necessitam de recursos específicos para a realização de tal processo. Não podemos esquecer que a função da escola é, em primeira instância, transmitir sistematicamente o conhecimento acumulado, não apenas a de socializar a criança, como muitas instituições escolares estão fazendo em nome da Educação Inclusiva. 
De acordo com o inciso X, o egresso do curso de Pedagogia deve "demonstrar consciência da diversidade, respeitando as diferenças de natureza ambiental-ecológica, étnico-racial, de gênero, faixas geracionais, classes sociais, religiões, necessidades especiais, escolhas sexuais, entre outras" (idem, ibidem, grifos nossos). Somente demonstrar consciência e respeitar as diferenças não parecem ser habilidades suficientes para formar um profissional que irá desenvolver atitudes sociais em relação à inclusão de pessoas com deficiência. Michels (2011), ao analisar as propostas de formação em Educação Especial, afirma que após a publicação das diretrizes há uma tendência de formação em cursos de pós-graduação lato sensu (muitos a distância) e na formação continuada. No entanto, ainda se observam uma desarticulação entre educação comum e especial (inclusive o atendimento educacional especializado), a ausência da discussão sobre práticas pedagógicas e

uma preponderância nas formações de um modelo que secundariza o pedagógico e privilegia o médico-psicológico. Tal encaminhamento pode sinalizar que a proposta de inclusão em curso no país não pressupõe a apropriação do conhecimento por parte dos alunos com deficiência. (idem, p. 229)

Como é possível perceber, o curso de Pedagogia passa por uma reformulação para sua adequação às necessidades políticas e sociais, e as diretrizes lançadas (Brasil, 2006) apontam os rumos pelos quais se reestruturaram os cursos de Pedagogia e muitas instituições de ensino superior tiveram de se adequar às exigências educacionais. Entre elas, encontramos a UNESP.

Essa instituição pública de ensino superior, especificamente o campus de Marília, visando reformular sua matriz curricular e se adequar à resolução de 15 de maio de 2006, promoveu entre os dias 12 e 14 de setembro de 2006 a XI Jornada Pedagógica: Diretrizes Curriculares Nacionais para o Curso de Pedagogia. Nesse evento, houve cinco GTs para discutir uma possível reformulação das diretrizes e em todos eles houve a participação de um representante do Departamento de Educação Especial para suscitar o debate acerca da Educação Inclusiva e suas implicações no processo de formação do pedagogo. Além dessa participação geral, houve um GT específico para discutir a "Implementação das políticas de Educação Inclusiva na formação do pedagogo". Nesse grupo, discutiu-se também a confusão conceitual de Educação Inclusiva, uma vez que as diretrizes não observam e não reconhecem, como mostramos em parágrafos anteriores, "a diferença essencial que há entre a Educação Especial e outras 'educações', já que nela estamos lidando com alunos que não são apenas diferentes, mas deficientes" (Oliveira; Giroto; Poker, 2006, p. 25). ${ }^{8}$

Nesse grupo ainda se discutiu que, mesmo os pedagogos tendo em sua formação geral e inicial a base teórica sobre a conceituação e tipologia das deficiências,

8 O leitor interessado no assunto sobre a formação em educação especial pode reportarse a Denari (2004, 2006); Ferreira (2004); Oliveira (2009, 2012); Prieto (2007, 2009). 
faltam lhes os conhecimentos didático-práticos "de ensino adequado a todos os alunos, com vistas a diferenciar, facilitar ou adequar objetivos, atividades, conteúdos e propostas curriculares que só a Educação Especial pode oferecer" (idem, p. 27). Acreditamos que se devem criar estratégias para uma formação conjunta, no qual o pedagogo domine os conteúdos e estratégias das teorias educacionais e amplie sua formação para o trabalho participativo, que deve ser realizado nas instituições de ensino escolar e não escolar. Esse trabalho participativo ou "colaborativo", como disse Peterson (2006), deve fazer parte da formação do pedagogo, uma vez que uma formação com especialização e aprofundamento em Educação Especial só tende a enriquecer a dinâmica intrínseca do processo de ensino-aprendizagem.

Assim, parece que é evidente a necessidade da formação de um profissional que domine os fundamentos educacionais, metodologias de ensino, práticas pedagógicas e também os conhecimentos teóricos e práticos sobre as necessidades específicas de cada deficiência. Oliveira (2009, p. 260), ao analisar as DCNs para o curso de Pedagogia, declara que a extinção das habilitações, principalmente a de Educação Especial, seguiu a "lógica do mercado educacional". Ainda para essa autora, a eliminação das habilitações demonstra uma visão simplista de Educação Inclusiva e "esvazia o papel da Educação Especial" (2009, p. 261) do processo de ensino aprendizagem dos alunos com deficiência.

Ao analisar a trajetória da formação de professores em Educação Especial, Oliveira (2012) verifica que o modelo dicotômico da formação dos professores do ensino regular proposto pelas habilitações precisaria realmente ser repensado, mas nos submeter à "lógica do mercado educacional" e optar por cursos de especializações sem critérios claros não seria o melhor caminho.

Embora se possa localizar a crítica à organização da Educação Especial como habilitação nos cursos de Pedagogia, outras universidades também, apesar de suas reformulações, mantiveram a proposta de Educação Especial de forma bastante evidente e tendo clareza o seu papel diferenciado na perspectiva inclusiva.É o caso da Universidade Federal de Santa Maria (UFSM) (Freitas, 2009), que mantém uma licenciatura na área, e da Universidade Federal de São Carlos (UFSCar) (Mendes et al., 2010), que considerando a importância da formação propõe, também como a UFSM, uma licenciatura em Educação Especial.

Cartolano (1998), ao comentar a reestruturação da proposta da UNICAMP, afirma que a formação em Educação Especial está presente no curso de Pedagogia desde 1987 e, mesmo com uma reflexão diferenciada perante uma perspectiva inclusiva, há a preocupação da manutenção desse conhecimento a todos os professores, porém também coloca a questão de se pensar na formação mais específica de professores que atuarão com alunos que apresentam maiores comprometimentos. Glat e Pletsch (2010), docentes da Universidade Federal do Rio de Janeiro (UFRJ) também apontam a importância de a universidade manter a formação de professores especialistas, tanto na formação inicial quanto na continuada.

Oliveira assinala, com bons olhos, os esforços despendidos pela comissão de reestruturação do curso de Pedagogia da Faculdade de Filosofia e Ciências da 
UNESP, campus de Marília, uma vez que desde o primeiro ano de curso os alunos terão possibilidade de contato com a literatura específica, antes restrita às habilitações em Educação Especial. Para essa autora, havemos de

[...] reconhecer o salto de qualidade na nova estrutura do curso, afinado com as políticas de educação inclusiva e buscando uma articulação entre a prática cotidiana das escolas, o enfrentamento das diferenças e das deficiências no interior das salas de aula e a formação docente na educação infantil e nas séries iniciais do ensino fundamental. (Oliveira, 2009, p. 263)

Uma proposta como essa talvez seja uma das possíveis saídas para a formação do professor e o que de fato uma Educação Inclusiva necessite.

Oliveira (2009, p. 270) argumenta que no processo de formação de professores, para efetivar um ensino de qualidade, temos mais questionamentos que respostas, mas dentro desse cenário de formação podemos ter uma certeza: a de que "é imprescindível uma formação diferenciada para o professor de Educação Especial, vinculada à formação pedagógica".

Essa certeza anunciada por Oliveira também a temos. O que nos resta saber é como os pesquisadores e estudiosos da área se posicionarão perante o árduo e dispendioso trabalho que está por vir.

Prieto (2009) também afirma que a extinção da habilitação deixou muitas lacunas para a formação do especialista para atuar na Educação Especial. Hoje, para essa pesquisadora da área, temos mais questionamentos que conclusões. Para Prieto, assim como para Oliveira (2009), há que se pensar sobre os cursos de especialização lato sensu.

Ainda para Prieto, outro fator que se anuncia com a não formação do especialista na graduação é o risco que corre a própria área de conhecimento em Educação Especial, que vem ao longo das últimas décadas se destacando e expandindo com significativa expressão dentro das universidades brasileiras. A autora, ao analisar o desmonte da formação do especialista em Educação Especial, identifica sérios problemas para a área:

- As universidades públicas tendem a privilegiar, para fins de cômputo da carga didática dos docentes, a sua atuação em cursos de graduação e em pós-graduação, o que desestimula o investimento na concretização de cursos lato sensu;

- A abertura de vaga na instituição para a contratação de professores não pode ser feita a partir de editais com disciplinas de cursos de especialização. Em decorrência disso, à medida que os professores de Educação Especial das instituições superiores públicas se aposentarem ou se deslocarem para outras atividades, dentro ou fora da unidade, se as regras continuarem as mesmas, seus cargos não poderão ser ocupados por profissionais com essa 
formação, pois os cursos de graduação em Pedagogia - com habilitação em Educação Especial - que permitam essa via de entrada não mais existirão;

- Como consequência, a produção científica na área pode ser muito comprometida, pois são esses os professores credenciados para orientar pesquisas em nível de pós-graduação, de iniciação científica, responsáveis pela condução de grupos de estudos, pelo desenvolvimento de suas próprias pesquisas, dentre outras atividades com estreita relação com o atendimento educacional especializado. (Prieto, 2009, p. 284)

Uma das preocupações que podemos citar é a formação de estudantes de Pedagogia para a Educação Inclusiva, mas ao tocar nesse tema acabamos discutindo a necessidade dos especialistas, antes formados nas habilitações em Educação Especial. Percebemos que nesse processo de extinção das habilitações não só o desenvolvimento da formação de recursos humanos indispensáveis para a efetivação da Educação Inclusiva foi prejudicado, mas vemos que a alteração também pode comprometer muitos anos de pesquisas pelos quais pesquisadores consagrados se firmaram e se destacaram no cenário nacional e internacional.

Prieto (2009) argumenta que as diretrizes citam sugestões para se pensar na formação desses especialistas em Educação Especial com aprofundamentos ou diversificação de estudos (Brasil, 2006).

Outro registro da citada autora é a possibilidade traçada pela resolução n. 2 de 2001, que prevê a formação do especialista "em cursos de licenciatura em Educação Especial ou em uma de suas áreas, preferencialmente de modo concomitante e associado à licenciatura para Educação Infantil ou para as séries iniciais do Ensino Fundamental" (Brasil, 2001).

Esse é o cenário no qual o curso de Pedagogia está inserido: um curso com identidade legitimada e sem habilitações, mas com um papel fundamental para que uma educação de qualidade se efetive.

Vivemos em uma sociedade dinâmica em que transformações ocorrem, algumas lentamente, outras nem tanto. Mas havemos de convir que é esse transformar que constitui a própria dialética implícita nas sociedades.

Esse caráter dinâmico também se apresenta na história da constituição dos cursos de Pedagogia da UNESP, como veremos a seguir.

\section{O CURSO DE PEDAGOGIA DA UNIVERSIDADE ESTADUAL PAULISTA}

O curso de Pedagogia da UNESP foi criado anteriormente à constituição da própria universidade, uma vez que ela é proveniente das Faculdades de Filosofia, Ciências e Letras do interior do estado de São Paulo, também conhecidas como Institutos Isolados de Ensino Superior. Para Vaidergon (1995), a criação desses institutos isolados, entre 1957 e 1959, ocorreu por interesses econômicos e sociais de uma oligarquia de mando político local, que via na educação uma estratégia para o desenvolvimento. Seu modelo se inspirou na Faculdade de Filosofia, Ciências e 
Letras ${ }^{9}$ da USP. ${ }^{10}$ A finalidade desses institutos "era a formação de professores secundários, no rico interior paulista, o qual era cônscio da possibilidade de acesso à cultura e de seus quadros, cuja demanda [...] a USP não dava conta" (idem, p. 156-157).

O curso de Pedagogia foi um dos primeiros a funcionar nos Institutos Isolados de Ensino Superior. Para Vaidergon (1995, p. 160), o curso surgiu como uma consequência das licenciaturas e, uma vez que "deveriam ser obrigatoriamente instaladas as disciplinas de formação didática e pedagógica para as licenciaturas, tornava-se fácil incluir Pedagogia e esta suprir aquela necessidade”.

Os Institutos Isolados de Ensino Superior de Marília e de Presidente Prudente tinham como objetivo formar professores secundários para atuação em escolas do interior. O Instituto de Araraquara mesclava seus objetivos entre a formação do professor e do pesquisador. O Instituto de Rio Claro surgiu pelo interesse da população local na formação de professores. O Instituto de São José do Rio Preto, composto pelos docentes tidos como os "rebeldes" da USP, tentou inovar o sistema administrativo e pedagógico, adotando o modelo departamental na Pedagogia, “com representação e participação dos alunos de forma paritária” (idem, p. 166-167).

O primeiro curso de Pedagogia dos Institutos Isolados Superiores a ser instalado foi o de São José do Rio Preto, em 1957; os de Araraquara, Marília, Presidente Prudente e de Rio Claro só foram criados em 1959. Esses institutos se mantiveram até 1976, sendo extintos em 30 de janeiro de 1976, passando então a compor a UNESP, que fora criada com a lei estadual n. 952, de 30 de janeiro de 1976 (Pagotto, 1995; Vaidergon, 1995). Segundo Haidar (apud Pagotto, 1995), a criação da UNESP se deu pela intenção do Conselho Estadual de Educação (CEE) de unir os Institutos Isolados do interior em um único organismo.

Segundo Pagotto (1995, p. 61), a UNESP foi criada para isentar a Secretaria Estadual de Educação da responsabilidade do ensino superior, uma vez que ela "pretendia dedicar-se exclusivamente aos ensinos de $1^{\circ}$ e $2^{\circ}$ graus". Inicialmente, no conselho havia se pensado em Federação de Institutos Isolados de Ensino Superior; entretanto, por se caracterizar como uma redundância, uma vez que a própria constituição dos institutos já os caracterizava como uma federação, surgiu a proposta - que se efetivou - de Universidade Estadual Paulista "Júlio de Mesquita Filho", sendo uma homenagem ao jornalista paulista. ${ }^{11}$

De acordo com Pagotto (1995), a criação da UNESP se fez valer sobretudo da vontade política do professor Luis Ferreira Martins, responsável pela Coordenadoria do Ensino Superior do Estado de São Paulo (CESESP), que após a criação da UNESP foi nomeado como seu primeiro reitor. Para Nagle (apud Pagotto, 1995,

9 Segundo Vaidergon, até 1957, a única faculdade pública de Filosofia, Ciências e Letras do estado de São Paulo era a da USP.

10 Vaidergon argumenta que a Faculdade de Filosofia Ciências e Letras da USP apresentou muita resistência à constituição de tais institutos, uma vez que eles poderiam desvirtuar o objetivo de formar e renovar as elites dirigentes.

11 Segundo Fernando Azevedo, "o mais ardente propugnador da ideia de criação de uma Universidade em São Paulo” (apud Vaidergon, 1995, p. 63). 
p. 62), "a sua indicação para ocupar o cargo de Reitor da UNESP foi o coroamento dos esforços que fizera para a sua criação". E, para Pagotto, a gestão de tal reitor se mostrou extremamente autoritária, centralizadora e burocrática.

Ainda conforme Pagotto (1995, p. 64), com a criação da UNESP algumas perdas se fizeram aos Institutos Isolados, uma vez que foram extintas sete faculdades de Filosofia e quinze cursos de graduação, dos quais treze eram da área de Ciências Humanas, obedecendo assim ao "princípio da não duplicação de meios e de recursos" que era proposto pela gestão naquele momento. Dessa forma, os cursos de Pedagogia que eram oferecidos em Presidente Prudente, Rio Claro e São José do Rio Preto foram extintos. Os docentes foram alocados nos campi de Araraquara e Marília.

O intuito da centralização dos docentes nessas duas unidades era o de formar grandes centros de excelência na área da educação e eliminar os departamentos. Pagotto (1995, p. 66), ao analisar a argumentação de Haidar sobre o processo de criação dos centros de excelência, cita quatro ideias centrais contidas em seu bojo:

[...] 10) os Departamentos de Educação eram avaliados cientificamente como pouco produtivos e sem direção; $2^{\circ}$ ) a proposta dos Centros de Excelência só seria reconhecida como boa pelos docentes realmente empenhados em crescer nas pesquisas da área, ou seja, só pelos "iluminados", 3) os professores da área que não pertencessem às Instituições onde se localizariam os Centros de Excelência teriam que se deslocar para eles; $4^{\circ}$ ) o corpo, do qual se falava que deveria se ajustar às tarefas que lhe fossem atribuídas, se materializaria, sem dúvida, nos Departamentos de Educação, através de seus professores.

Como é possível verificar no indicativo de Pagotto, os departamentos de educação muitas vezes eram associados como sendo "departamentos de Pedagogia" por algumas unidades dos Institutos Superiores de Ensino Superior. Esses departamentos também eram associados às disciplinas ligadas às teorias educacionais e práticas pedagógicas e sempre foram motivos de descrédito na constituição da UNESP.

De acordo com a autora (1995), a proposta dos centros de excelência foi efetivada e para isso os departamentos de educação foram eliminados. Os docentes que constituíam tais departamentos foram transferidos para as unidades de Araraquara e de Marília ou se demitiram. Em 1980, os docentes que permaneceram foram remanejados para suas unidades anteriores, mas alocados em outros departamentos.

Segundo Pagotto (1995), se por um lado não era possível pensar numa nova proposta de formação de professores, então se deveria estudar e realizar essa formação nos centros de excelência, que na área da Pedagogia seria na Faculdade de Ciências e Letras, no campus de Araraquara, e na Faculdade de Filosofia e Ciências, no campus de Marília. Assim, todos os programas de ensino que seriam desenvolvidos nos cursos de licenciatura deveriam ser aprovados nos centros. Contudo, essa proposta se tornou inviável em virtude da grande burocratização que se dava no processo. Para Marini (apud Pagotto, 1995, p. 67), o que era possível perceber "nos cinco primeiros anos de UNESP foi o cultivo da meritocracia e a tecnoburocracia 
controlando uma estrutura autoritária pela centralização do poder e pela interferência nas atividades de ensino [,] pesquisa e extensão de serviços à comunidade".

Esse modelo que propôs a extinção dos cursos de Pedagogia era o cerne de sustentação das licenciaturas e constituía "uma das linhas fundamentais da política de formação de recursos humanos da Universidade e do Estado e um gesto de colaboração para com a expansão e crescimento das Licenciaturas das Faculdades privadas" (idem, ibidem).

Em 1984, sob outra administração geral da UNESP, os departamentos de educação foram recriados nas unidades com cursos de licenciatura. $\mathrm{O}$ curso de Pedagogia de Rio Claro foi reaberto em 1986, o de Presidente Prudente em 1988, o de São José do Rio Preto em 2001 e o de Bauru é criado em 2001. ${ }^{12}$ Os cursos compuseram assim três formas de organização, a saber:

10) O grupo dos cursos de Pedagogia constituídos com a criação dos Institutos Isolados de Ensino Superior e que não sofreram interrupções em sua trajetória institucional, como é o caso da Faculdade de Ciências e Letras, campus de Araraquara, e da Faculdade de Filosofia e Ciências, campus de Marília;

$2^{\circ}$ ) O grupo dos cursos de Pedagogia constituídos com a criação dos Institutos Isolados de Ensino Superior que tiveram interrupções na trajetória institucional com a criação da UNESP e foram depois reabertos, como é o caso da Faculdade de Ciências e Tecnologia, campus de Presidente Prudente, do Instituto de Biociências, campus de Rio Claro e do Instituto de Biociências, Letras e Ciências Exatas, campus de São José do Rio Preto;

3o) O grupo formado de um único elemento, até o momento, com o curso constituído por uma universidade já consolidada e respeitada academicamente, o curso de Pedagogia da Faculdade de Ciências, campus de Bauru.

Hoje, 2012, a UNESP oferece o curso de Pedagogia em seis unidades diferentes e distantes geograficamente umas das outras, a saber: (1) Faculdade de Ciências, campus de Bauru; (2) Faculdade de Ciências e Letras, campus de Araraquara; (3) Faculdade de Ciências e Tecnologia, campus de Presidente Prudente; (4) Faculdade de Filosofia e Ciências, campus de Marília; (5) Instituto de Biociências, campus de Rio Claro; (6) Instituto de Biociências, Letras e Ciências Exatas, campus de São José do Rio Preto.

Ao discutirmos a formação no curso de Pedagogia numa perspectiva inclusiva, ressaltamos que a UNESP foi a universidade pública estadual pioneira na formação de professores especializados para o ensino de pessoas com deficiência, pois desde 1977 ofereceu a habilitação em Educação Especial. Inicialmente, essa formação se dava apenas na Faculdade de Filosofia e Ciências, campus de Marília, e a partir de 1986 também passa a ser oferecida pela Faculdade de Ciências e Letras

12 A Universidade de Bauru foi incorporada à UNESP posteriormente aos outros campi. Sua junção ocorreu em 1988 (Pagotto, 1995, p. 59). 
no campus de Araraquara (Omote, 1996). Essa estrutura se manteve até 2006; no entanto, com a publicação das DCNs para o curso de Pedagogia (Brasil, 2006) - a qual propõe a extinção das habilitações -, e por consequência da legislação, a formação ofertada por Marília e Araraquara também se extingue. Assim, o curso de Pedagogia da Faculdade de Filosofia e Ciências diplomou sua última turma em 2010, e o curso da Faculdade de Ciências e Letras ofereceu o eixo de formação em Educação Especial até o ano letivo de 2012.

Embora tenha suas origens conturbadas e em algumas unidades contrárias à formação de professores, a UNESP se tornou, ao longo desses 36 anos, uma das maiores instituições públicas formadoras de pedagogos em todo o interior paulista, sendo a universidade pública estadual pioneira na formação de recursos humanos para o exercício do magistério com pessoas deficientes. Os docentes dos cursos de Pedagogia da UNESP possuem produções científicas nacionais e internacionais nas mais variadas áreas do conhecimento, hoje se destacando no cenário científico-acadêmico.

As diretrizes, por sua vez, embora mencionem a importância da formação numa perspectiva inclusiva, não definem a formação específica em Educação Especial, que era então mantida pelas habilitações. Se, por um lado, era realmente necessário avançar na proposta de uma formação mais sólida e menos fragmentada, por outro, formar professores aptos a lidarem com a Educação Inclusiva e com as necessidades educacionais especiais não elimina o mérito da formação em Educação Especial, uma vez que o professor especialista deverá compor uma rede de apoio pedagógico por meio de um atendimento educacional especializado que garanta a aprendizagem de todos os alunos, inclusive daqueles com deficiência, transtornos invasivos do desenvolvimento e com altas habilidades.

Esse especialista poderia orientar a escola, o professor, a família, e ainda desenvolver materiais, recursos, estratégias e métodos para que a inclusão escolar aconteça em sua plenitude. No entanto, sua formação não pode estar desvinculada da formação pedagógica, e é aí que se instalou a dificuldade imposta pela extinção das habilitações.

Atualmente, no âmbito do estado de São Paulo e graças à intervenção da pró-reitoria de graduação da UNESP, foi publicada a deliberação n. 94/2009 (São Paulo, 2009), que estabelece normas para a formação de professores em nível de especialização para o trabalho com crianças com necessidades especiais no sistema de ensino do estado de São Paulo, regulamentando cursos de especialização na área da Educação Especial e resgatando a importância fundamental desse profissional.

No que se refere à formação pela perspectiva da Educação Inclusiva, a Faculdade de Filosofia e Ciências, campus de Marília, incluiu em seu PPP a discussão sobre o assunto com a inserção de seis disciplinas e a possibilidade de ocorrer no segundo semestre do quarto ano a realização de um aprofundamento na área.

Como pudemos perceber ao longo do texto, a estruturação do curso de Pedagogia, em toda a sua trajetória, sofre as influências do pensamento científico e social sobre a formação de professores. Não foi diferente na trajetória dos cursos 
da UNESP, que, sensível às mudanças substanciais que ocorreram no universo das práticas pedagógicas e na organização dos sistemas de ensino, busca responder aos anseios sociais e às necessidades prementes na constituição de novas proposições pedagógicas e formativas.

Toda a história e trajetória dos cursos de Pedagogia da UNESP e sua forte atuação no estado de São Paulo concederam-lhe amplo reconhecimento nacional no que se refere aos três pilares que sustentam as universidades públicas: o ensino, a pesquisa e a extensão universitária, pois suas propostas se apoiam em sua produção científica, derivada de sua intrínseca relação com a prática cotidiana das escolas paulistas.

\section{CONSIDERAÇÕES FINAIS}

Ao longo deste trabalho, argumentamos que a constituição histórica dos cursos de Pedagogia da UNESP foi firmando-se entre inúmeros conflitos existentes no bojo das crises de identidade do curso e nos conflitos oriundos da própria criação da instituição.

Durante esses 36 anos de criação dos cursos de Pedagogia da UNESP, alguns deles se mantiveram, outros foram fechados e depois reabertos, e outros foram criados recentemente. Atualmente, o curso é composto por três grupos. $\mathrm{O}$ primeiro grupo é formado pelos cursos de Pedagogia que se constituíram com a criação dos Institutos Isolados de Ensino Superior e que não sofreram interrupções na trajetória institucional, como é o caso da Faculdade de Ciências e Letras, campus de Araraquara, e da Faculdade de Filosofia e Ciências, campus de Marília. O segundo grupo é formado por cursos que se constituíram com a criação dos Institutos Isolados de Ensino Superior e que tiveram interrupções na trajetória institucional com a criação da UNESP e foram depois reabertos, como é o caso da Faculdade de Ciências e Tecnologia, campus de Presidente Prudente, do Instituto de Biociências, campus de Rio Claro, e do Instituto de Biociências, Letras e Ciências Exatas, campus de São José do Rio Preto. O terceiro grupo é formado de um único elemento, cujo curso foi constituído em uma universidade consolidada e respeitada academicamente, o curso de Pedagogia da Faculdade de Ciências, campus de Bauru.

Nessa trajetória histórica, os cursos de Pedagogia que constituíram o primeiro grupo citado - talvez com os fundamentos de centros de excelência em educação criaram as habilitações em Educação Especial. Na Faculdade de Filosofia e Ciências, no campus de Marília, em 1977, o curso de Pedagogia ofereceu a habilitação em Educação Especial nas quatro áreas: Deficiência Auditiva, Deficiência Intelectual, ${ }^{13}$ Deficiência Física e Deficiência Visual. Na Faculdade de Ciências e Letras, campus de Araraquara, em 1986 o curso de Pedagogia ofereceu a habilitação em Deficiência Intelectual. Essa formação se manteve até 2006; no entanto, com a publicação

13 Em outros artigos, o leitor poderá encontrar a expressão deficiência mental para designar o que hoje a literatura da área grafa como deficiência intelectual. 
das DCNs para o curso de Pedagogia (Brasil, 2006), que propõem a extinção das habilitações, a formação ofertada por Marília e Araraquara também se extingue.

Mesmo com a extinção das habilitações, o curso de Pedagogia da Faculdade de Filosofia e Ciências manteve em sua matriz curricular, na formação básica de seus estudantes, disciplinas que contemplavam a temática da Educação Especial. Entre os cursos de Pedagogia da UNESP, esse foi o único a manter o aprofundamento voltado para a Educação Especial, como apontado por Oliveira (2012), em virtude da participação ativa dos docentes do Departamento de Educação Especial no processo de reestruturação da nova matriz curricular dessa unidade universitária.

Essa atuação dos docentes e dos pesquisadores demonstra a importância da área na busca de uma educação na perspectiva inclusiva.

\section{REFERÊNCIAS}

Aguiar, Márcia Ângela da Silva; Brzezinski, Iria; Freitas, Helena Costa Lopes de; Silva, Marcelo Soares Pereira da; PIno, Ivany Rodrigues. Diretrizes curriculares do curso de pedagogia no Brasil: disputas de projetos no campo da formação do profissional da educação. Educaşão É Sociedade, Campinas: CEDES, v. 27, n. 96, p. 819-842, out. 2006. Especial. Disponível em: <http://www.cedes.unicamp.br>. Acesso em: 23 maio 2010.

Aranha, Maria Lúcia de Arruda. História da educação. São Paulo: Moderna, 2000.

Brasil. Presidência da República. Decreto-lei n. 1.190, de 4 de abril de 1939. Dá organização à Faculdade Nacional de Filosofia. Diário Oficial da União, Brasília, DF, 6 abril 1939. Seção 1, p.7.929.

Presidência da República. Decreto-lei n. 4.024, de 20 de dezembro de 1961. Fixa Diretrizes e Bases da Educação Nacional. Diário Oficial da União, Brasília, DF, 27 dezembro 1961. Seção 1, p.11.429.

Conselho Federal de Educação. Parecer n. 251/62. Currículo mínimo e duração do curso de pedagogia. Relator: Valnir Chagas.Documenta, Brasília, DF: [s.n.], n. 11, 1963.

Conselho Federal de Educação. Portaria n. 252/69 da Comissão Central de Revisão dos Currículos, aprovado em 11 de abril de 1969. Relator: Valnir Chagas. Documenta, Brasília, DF: [s.n.], n. 100, p. 101-136, 1969a.

Ministério da Educação. Conselho Nacional de Educação. Resolução CFE n. 2/69, de 12 de maio de 1969. Reformula o curso de Pedagogia e propõe habilitações no último ano. Diário Oficial da União, Brasília, DF, 1969b, 12 maio.

.Presidência da República. Decreto-lei n. 5.540, de 28 de novembro de 1968. Fixa normas de organização e funcionamento do ensino superior e sua articulação com a escola

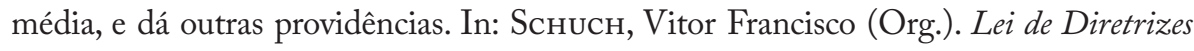
e Bases da Educação Nacional e Magistério. 4. ed. Porto Alegre: Sulina, 1972a. p. 98-110.

. Presidência da República. Decreto-lei n. 5.692, de 11 de agosto de 1971. Fixa diretrizes e bases para o ensino de $1^{\circ}$ e $2^{\circ}$ graus, e dá outras providências. In: $\mathrm{S} \mathrm{cHUCH}$, 
Vitor Francisco (Org.). Lei de Diretrizes e Bases da Educação Nacional e Magistério. 4. ed. Porto Alegre: Sulina, 1972b. p. 65-83.

Presidência da República. Decreto-lei n. 9.394, de 20 de dezembro de 1996. Estabelece as diretrizes e bases da educação nacional. Diário Oficial da União, Brasília, DF, 23 dezembro 1996. Seção 1, p. 27.833.

. Ministério da Educação. Conselho Nacional de Educação. Resolução CNE/CEB n. 2, de 11 de setembro de 2001. Institui Diretriz Nacional para a Educação Especial na Educação Básica. Diário Oficial da União, Brasília, DF, seção 1E, p. 39-40, 14 set. 2001.

. Ministério da Educação. Conselho Nacional de Educação. Resolução CNE/CP n. 1. Aprovada em 15 de maio de 2006. Institui Diretrizes Curriculares Nacionais para o Curso de Graduação em Pedagogia, Licenciatura. Diário Oficial da União, Brasília, DF, seção 1, p. 11, 16 maio 2006.

Brzezinski, Iria. Pedagogia, pedagogos e formação de professores. 4. ed. Campinas: Papirus, 2002.

Bueno, José Geraldo Silveira. Crianças com necessidades educativas especiais, política educacional e a formação de professores: generalistas ou especialistas? Revista Brasileira de Educação Especial, Piracicaba: UNIMEP, v. 3, n. 5, p. 7-25, set. 1999.

CAMbi, Franco. História da pedagogia. Tradução de Álvaro Lorenci. São Paulo: Fundação Editora da UNESP, 1999. $701 \mathrm{p}$.

Cartolano, Maria Teresa Penteado. Formação do educador no curso de pedagogia: a educação especial. Cadernos CEDES, Campinas: CEDES, ano XIX, n. 46, p. 29-40, set. 1998.

Denari, Fátima Elisabeth. Formação de professores em educação especial: a ótica do GTEE-06 e do Fórum Permanente de Educação Especial. In: Омоте, Sadao (Org.). Inclusão: intenção e realidade. Marília: FUNDEPE, 2004. p. 61-76.

. Um (novo) olhar sobre a formação de educação especial: da segregação à inclusão. In: Rodrigues, David (Org.). Inclusão e educação: doze olhares sobre a educação inclusiva. São Paulo: Summus, 2006. p. 35-63.

Ferreira, Maria Cecília Cacareto. Formação de professores. In: Mendes, Enicéia Gonçalves; Almeida, Maria Amélia; Willians, Lúcia Cavalcanti de Albuquerque (Orgs.). Temas em educação especial: avanços recentes. São Carlos: EDUFSCar, 2004. p. 251-256.

Freitas, Soraia Napoleão. A formação docente sob a ótica da diversidade e da inclusão. In: Martins, Lúcia de Araújo Ramos; Pires, José; Pires, Glaúcia Nascimento da Luz. Políticas e práticas educacionais inclusivas. Natal: EDUFRN, 2009. p. 93-115.

GAtтi, Bernadete Angelina. Licenciaturas: crise sem mudança? In: DAlben, Ângela Imaculada Loureiro de Freitas; Diniz, Júlio; Leal, Leiva; SAnTos, Lucíola. Convergências e tensões no campo da formação e do trabalho docente. Belo Horizonte: Autêntica, 2010. p. 485-509. (Didática e prática de ensino). 
Giroto, Claudia Regina Mosca; Castro, Rosane Michelli. A formação de professores para a educação inclusiva: alguns aspectos de um trabalho colaborativo entre pesquisadores e professores da educação infantil. Revista Educação Especial, Santa Maria: UFSM, v. 24, n. 41, p. 441-452, set./dez. 2011.

Glat, Rosana; Pletsch, Márcia Denise. O papel da universidade no contexto da política de educação inclusiva: reflexões sobre a formação de recursos humanos e a produção de conhecimento. Revista Educação Especial, Santa Maria: UFSM, v. 23, n. 38, p. 345-356, set./dez. 2010.

JAEger, Werner. Paidea: a formação do homem grego. Tradução de Artur M. Parreira. São Paulo: Herder, [19--].1.343 p.

LibÂneo, José Carlos. Pedagogia e pedagogos, para quê? São Paulo: Cortez, 1998. 200 p.

Luzuriaga, Lorenzo. História da educação e da pedagogia. 3. ed. São Paulo: Companhia Nacional, 1955.

Marrou, Henri-Irenee. História da Antiguidade. São Paulo: Herder, 1966.

Mendes, Enicéia Gonçalves. Inclusão escolar com colaboração: unindo conhecimentos, perspectivas e habilidades profissionais. In: Martins, Lúcia de Araújo Ramos; Pires, José; Pires, Glaúcia Nascimento da Luz. Politicas e práticas educacionais inclusivas. Natal: EDUFRN, 2009. p. 19-51.

.; Almeida, Maria Amélia; Denari, Fátima Elisabeth; Costa, Maria da Piedade Resende. Professores de educação especial e a perspectiva da inclusão escolar: uma nova proposta de formação. In: Mendes, Enicéia Gonçalves; Almeida, Maria Amélia (Orgs.). Das margens ao centro: perspectivas para as políticas e práticas educacionais no contexto da educação especial inclusiva. Araraquara: Junqueira\&Marin, 2010. p. 123-139.

Michels, Maria Helena. O que há de novo na formação de professores para a educação especial? Revista Educação Especial, Santa Maria: UFSM, v. 24, n. 40, p. 219-232, maio/ ago. 2011.

Naujorks, Maria Inês; Real, Daniela Corte; Mohr, Alana Claudia. Deficiência, cinema, imaginário e formação docente. Revista Educação Especial, Santa Maria: UFSM, v. 24, n. 41, p. 427-440, set./dez. 2011.

Oliveira, Anna Augusta Sampaio. Formação de professores em educação especial: a busca de uma direção. In: Mendes, Enicéia Gonçalves; Almeida, Maria Amélia; Willians, Lúcia Cavalcanti de Albuquerque (Orgs.). Temas em educaşão especial: avanços recentes. São Carlos: EDUFSCar, 2004. p. 239-243.

A política de formação de professores para educação especial: a ausência de diretrizes ou uma política anunciada? In: Pinho, Sheila Zambello de (Org.). Formação de educadores: o papel do educador e sua formação. São Paulo: Editora UNESP, 2009. p. 257-271.

Inclusão escolar e formação de professores: o embate entre o geral e o específico. In: Mendes, Enicéia Gonçalves; Almeida, Maria Amélia (Orgs.). Das margens ao centro: 
perspectivas para as políticas e práticas educacionais no contexto da educação especial inclusiva. Araraquara: Junqueira\&Marin, 2010. p. 141-150.

. Educação especial: a formação do professor em debate. In: Chacon, Miguel Cláudio Moriel; Marin, Maria José Sanches (Orgs.). Educação e saúde de grupos especiais. Marília: Oficina Universitária; São Paulo: Cultura Acadêmica, 2012. p. 27-44.

.; Giroto, Cláudia Regina Mosca; Poker, Rosimar Bortolini. Implementação das políticas de educação inclusiva na formação do pedagogo. In: Jornada Pedagógica: Diretrizes Curriculares Nacionais para o Curso de Pedagogia, 11., 2006, Marilia. Resumos... Marilia: SAEPE, 2006. p. 23-31.

Омоте, Sadao. Dificuldades e perspectivas para habilitação em educação especial. Revista Brasileira de Educaşão Especial, Marília: ABPEE, v. 2, n. 4, p. 127-135, 1996.

Pagotto, Maria Dalva Silva. A UNESP e a formação de professores. 1995. 278f. Tese (Doutorado em Educação) - Faculdade de Educação, Universidade Estadual de Campinas, Campinas, 1995.

Peterson, Patrícia Jason. Inclusão nos Estados Unidos: filosofia, implementação e capacitação de professores. Revista Brasileira de Educação Especial, Marília: ABPEE; FFC - UNESP Publicações, v. 12, n.1, p. 3-12, 2006.

Piccolo, Gustavo Martins. As bases do processo de formação docente voltado à inclusão. Revista Educação Especial, Santa Maria: UFSM, v. 22, n. 35, p. 363-374, set./dez. 2009.

Prieto, Rosângela Gavioli. Professores especializados de um centro de apoio: estudo sobre saberes necessários para sua prática. In: Jesus, Denise Meyrelles; BAptista, Cláudio Roberto; Barreto, Maria Aparecida Santos Corrêa; Victor, Sônia Lopes (Orgs.). Inclusão, práticas pedagógicas e trajetórias de pesquisa. Porto Alegre: Editora Mediação, 2007. p. 281-294.

Educação inclusiva com ênfase no atendimento de alunos com necessidades educacionais especiais: qual formação de professores? In: Pinho, Sheila Zambello de (Org.). Formação de educadores: o papel do educador e sua formação. São Paulo: Editora UNESP, 2009. p. 271-287.

Saviani, Dermeval. Pedagogia: o espaço da educação na universidade. Cadernos de Pesquisa, São Paulo: Fundação Carlos Chagas; Campinas: Autores Associados, v. 37, n. 130, p. 1-16,jan./abr. 2007.

.A pedagogia no Brasil: história e teoria. Campinas: Autores Associados, 2008.259 p. São Paulo. Assembleia Legislativa do Governador do Estado de São Paulo. Lei n. 952, de 30 de janeiro de 1976. Cria a Universidade Estadual Paulista "Julio de Mesquita Filho" e dá providências correlatas. Diário Oficial do Estado, São Paulo, n. 21, p.1-2,31 jan. 1976. . Conselho Estadual de Educação. Deliberação CEE n. 94/2009. São Paulo: CEE, 2009.

Scheibe, Leda. Diretrizes nacionais para os cursos de pedagogia: da regulação à implementação. In: DaLben, Ângela Imaculada Loureiro de Freitas; Dinız, Júlio; LeAL, 
Leiva; SAntos, Lucíola. Convergências e tensões no campo da formação e do trabalho docente. Belo Horizonte: Autêntica, 2010. p. 551-568. (Didática e prática de ensino).

Scheibe, Leda; Aguiar, Márcia Ângela. Formação de profissionais no Brasil. O curso de pedagogia em questão. Educação E Sociedade, Campinas: CEDES, v. 20, n. 68, p. 220238, dez. 1999.

Silva, Carmem Silvia Bissoli da. Curso de pedagogia no Brasil: história e identidade. 3. ed. Campinas: Autores Associados, 2006. 112 p. (Coleção polêmicas do nosso tempo, 66).

Silva Júnior, Celestino Alves da. Arguição na banca de defesa de doutoramento de Cristiane Regina Xavier Fonseca-Janes. In: Fonseca-Janes, Cristiane Regina Xavier. $A$ formação dos estudantes de pedagogia para a educação inclusiva: estudo das atitudes sociais e do currículo. 2010. 269f. Tese (Doutorado em Educação) - Faculdade de Filosofia e Ciências, Universidade Estadual Paulista, Marília, 2010.

Silva, Maria de Lourdes Ramos da. O curso de pedagogia em busca de sua identidade: as contribuições da deliberação CEE n. 78/2008. Revista Internacional d'Humanitats, São Paulo: Feusp; Barcelona: Universitat Autònoma de Barcelona, n. 17, p. 27-38, set./ dez. 2009.

TANURI, Leonor Maria. História da formação de professores. Revista Brasileira de Educação, São Paulo: Universidade de São Paulo, n. 14, p. 61-88, maio/ago. 2000.

VAidergon, José. As seis irmãs: as Faculdades de Filosofia, Ciências e Letras - Institutos Isolados de Ensino Superior do Estado de São Paulo - 1957-1964: alguns subsídios interpretativos para o estudo do ensino superior do estado de São Paulo. 1995. 213f. Tese (Doutorado em Educação) - Faculdade de Educação da Universidade Estadual de Campinas, Campinas, 1995.

\section{SOBRE OS AUTORES}

Cristiane Regina Xavier Fonseca-Janes é doutora em educação pela Universidade Estadual Paulista (UNESP).

E-mail: crisrefonseca@fundec.edu.br

Celestino Alves da Silva Júnior é doutor em educação pela Pontifícia Universidade Católica de São Paulo (PUC-SP). Professor titular (aposentado) da mesma instituição.

E-mail: celestino.silva@uol.com.br

Anna Augusta Sampaio de Oliveira é doutora em educação pela Universidade Estadual Paulista (UNESP). Professora da mesma instituição. E-mail: hanamel@terra.com.br 


\section{CRISTIANE REGINA XAVIER FONSECA-JANES, CELESTINO ALVES} DA SILVA JÚNIOR E ANNA AUGUSTA SAMPAIO DE OLIVEIRA

\section{Pedagogia, educação especial e educação inclusiva na UNESP:} história e trajetória

O presente artigo trata da constituição histórica dos cursos de pedagogia e de sua proposta atual de formação para a docência e para a gestão de sistemas educacionais. Também são discutidos neste trabalho a constituição dos cursos de pedagogia da Universidade Estadual Paulista "Julio de Mesquita Filho" (UNESP), o movimento de cada um, suas especificidades, a relação com a tendência nacional, os aspectos políticos e ainda as implicações das diretrizes nacionais para a formação em educação especial e a perspectiva de educação inclusiva na formação de professores. Atualmente, a UNESP conta com seis cursos de pedagogia fortemente consolidados e atuantes no cenário educacional brasileiro na área do ensino, da extensão universitária e da pesquisa e, embora tenha caminhado para uma adequação com base nas diretrizes nacionais, 
cada curso mantém particularidades em seu projeto pedagógico. Em decorrência desse contexto e pela história da Faculdade de Filosofia e Ciências de Marília, encontramos uma organização que contempla a perspectiva de uma educação inclusiva.

Palavras-chave: curso de pedagogia; Universidade Estadual Paulista; formação de professores; educação inclusiva.

\section{Pedagogy, special education and inclusive education at UNESP: history and trajectory}

This article addresses the historical constitution of Pedagogy undergraduate courses and their current proposal for teacher education and for the management of education systems. Another aspect discussed in the text is the constitution of the Pedagogy undergraduate courses at UNESP, the movement of each one, its specificities, relationship with the national trend, political aspects, and also the implications of the national guidelines for training in special education and the inclusive education approach in teacher education. Nowadays, UNESP has six Pedagogy undergraduate courses that are strongly consolidated and active in the Brazilian educational scenario in the area of teaching, research and extension education, and although UNESP has progressed towards conforming the national guidelines, each course has peculiarities in its pedagogical projects. As a result of this and of the history of the FFC in Marilia, we found an organization that includes the perspective of an inclusive education.

Keywords: pedagogy undergraduate courses; Universidade Estadual Paulista; teacher education; inclusive education.

\section{Pedagogía, educación especial y educación inclusiva en la UNESP: historia y trayectoria}

Este articulo trata de la constitución histórica de la pedagogía y su actual propuesta de formación de docentes y la gestión de los sistemas educativos. Otro aspecto tratado en el texto es la constitución de los cursos de pedagogía de la Universidade Estadual Paulista "Julio Mesquita Filho" (UNESP), el movimiento de cada uno, sus características especificas, la relación con la tendencia nacional, los aspectos politicos, y también las implicaciones de las directrices nacionales para la formación en educación especial y el enfoque de educación inclusiva en la formación docente. En la actualidad, la UNESP tiene seis cursos de pedagogía fuertemente consolidados y activos en el escenario brasileño de educación en el área de la enseñanza, la extensión universitaria y de investigación, y aunque haya caminado hacia un ajuste basado en las directrices nacionales, cada curso mantiene sus peculiaridades en sus proyectos pedagógicos. Como resultado de esto y la bistoria de la Facultad de Filosofía y Ciencias en Marilia, encontramos una organización que incluye la perspectiva de una educación inclusiva.

Palabras clave: cursos de pedagogía; Universidade Estadual Paulista; la formación del profesorado; educación inclusive. 